\title{
Surgical anatomy of the juxtadural ring area
}

\section{Susumu Oikawa, M.D., Kazuhiko Kyoshima, M.D., and Shigeaki Kobayashi, M.D.}

Department of Neurosurgery, Shinshu University School of Medicine, Matsumoto, Japan

Object. The authors report on the surgical anatomy of the juxtadural ring area of the internal carotid artery to add to the information available about this important structure.

Methods. Twenty sides of cadaver specimens were used in this study. The plane of the dural ring was found to incline in the posteromedial direction. Medial inclination was measured at 21.8š on average against the horizontal line in the anteroposterior view on radiographic studies. Posterior inclination was measured at 20.3š against the planum sphenoidale in the lateral projection, and the medial edge of the dural ring was located $0.4 \mathrm{~mm}$ above the tuberculum sellae in the same projection. The lateral edge of the tuberculum sellae was located $1.4 \mathrm{~mm}$ below the superior border of the anterior clinoid process. The carotid cave was situated at the medial or posteromedial aspect of the dural ring; however, two of the 20 specimens showed no cave formation. The carotid cave contained the subarachnoid space in 13 sides, the arachnoid membrane only in three sides, and the extraarachnoid space in two sides. The authors propose that the marker of the medial side of the dural ring, which is more proximal than the lateral, is the tuberculum sellae in the lateral view on radiographic studies. In the medial aspect of the dural ring the intradural space can be situated below the level of the tuberculum sellae because of the existence of the carotid cave.

Conclusions. The authors found that an aneurysm arising from the medial side of the juxtadural ring area even below the tuberculum sellae is a potential cause of subarachnoid hemorrhage.

\section{Key Words * dural ring * carotid cave * surgical anatomy * juxtadural ring aneurysm}

The internal carotid artery (ICA) enters the intradural space through the dura mater in the side of the base of the anterior clinoid process forming the carotid siphon. $[2,6,7,16]$ This area is called the juxtadural ring area,[11] and therein are complicated anatomical structures, such as the proximal ring, distal dural ring, carotid cave, and clinoid space. $[4,9,10,12,19]$ The distal dural ring (also called the dural ring) is one of the most important structures in the surgery of juxtadural ring aneurysms of the ICA. $[1,3,5,8,11,13,14,20]$ Whether an aneurysm is proximal or distal to the dural ring influences surgical indications and the patients' prognosis. On the other hand, the anatomy of the carotid cave, which was introduced by Kobayashi, et al.,[10] as a site for aneurysm formation, is often misunderstood.[3,17] We report on the surgical anatomy of the juxtadural ring area, which we studied by means of anatomical and radiographic investigations performed in cadaver specimens.

\section{MATERIALS AND METHODS}


Twenty sides of cadaver specimens of the cavernous sinus and sphenoid bone that were fixed in formalin were used for this study to investigate inclination and location of the dural ring, and the incidence, location, depth, and contents of the carotid cave. At first, bone and structures around the dural ring were observed with the aid of an operative microscope. To examine the location of the dural ring, a metal ring was placed on it, and anteroposterior (AP) and lateral views were obtained on plain X-ray film (Fig. 1).

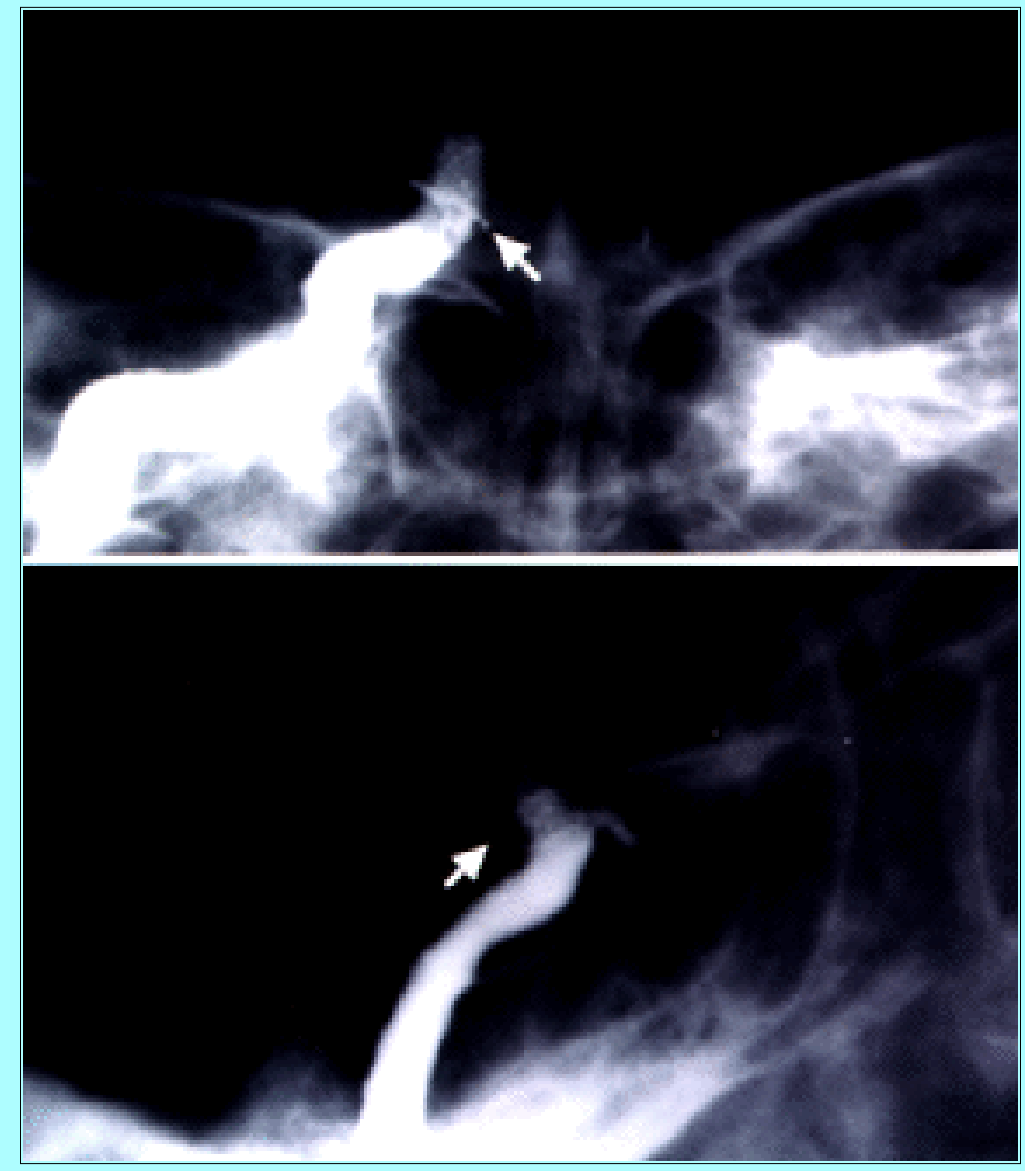

Fig. 1. Radiographic studies showing the dural ring and the ICA in a cadaver specimen. Metal ring (arrows) indicates the dural ring. Upper: An AP view. Lower: A lateral view. The dural ring inclines in the posteromedial direction.

Inclinations of the dural rings were measured against the horizontal line as the reference line in the AP view and against the plane of the planum sphenoidale as the reference line in the lateral view. In the lateral projection, the location of the dural ring was measured above the tuberculum sellae and below the superior border of the anterior clinoid process on the reference line, which is perpendicular to the planum sphenoidale on the tuberculum sellae (Fig. 2). We excluded specimens in which the appropriate reference lines could not be drawn for measurement. Incidence, location, depth, and contents of the carotid cave were studied with the aid of a surgical microscope. The location of the carotid cave was expressed with the superior view of the cross section of the right ICA regarded as the face of the clock: 12 o'clock was anterior, 3 o'clock lateral, 6 o'clock posterior, and 9 o'clock was medial. The left ICA was converted to the right for describing the location by the clock system. 


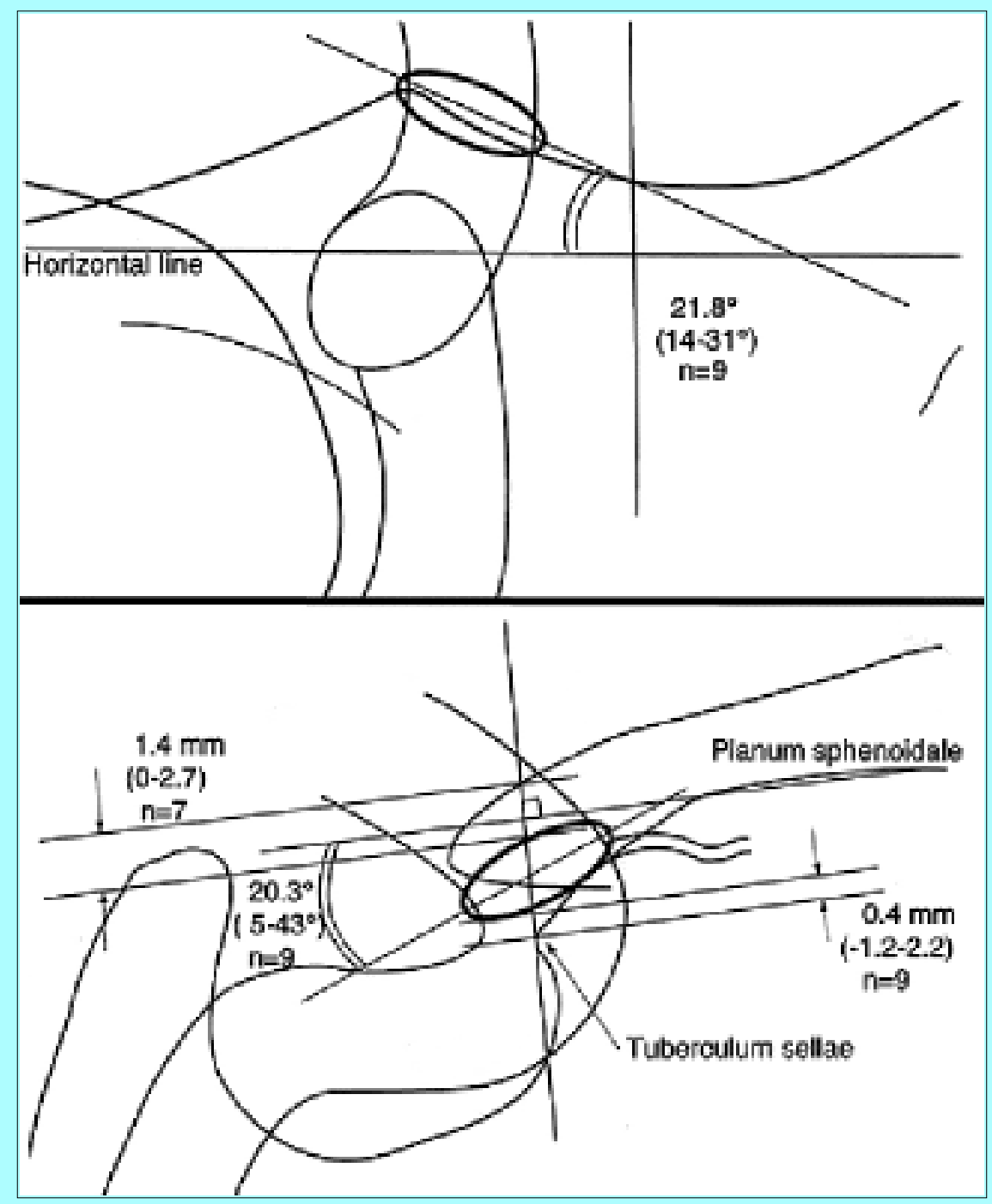

Fig. 2. Schematic drawings showing measurements of the right dural ring obtained by means of radiographic analysis. Upper: An AP view. Lower: A lateral view. The dural ring inclines posteromedially. The medial edge of the dural ring corresponds to the level of the tuberculum sellae in the lateral view. $\mathrm{n}=$ number of specimens.

\section{RESULTS}

\section{Dural Ring}

The dural ring is surrounded on three sides by bony structures; the anterior clinoid process is situated laterally, the optic strut anteriorly, and the middle clinoid process or tuberculum sellae medially or anteromedially. Posteriorly, the clinoid process is located far from the dural ring, which continues to the dura mater covering the anterior clinoid process laterally, to the dura mater of the optic canal anteriorly, to the dura mater covering the tuberculum sellae anteromedially, to the diaphragma sellae posteromedially, and to the dura mater covering the posterior clinoid process posteriorly (Fig. 3). 


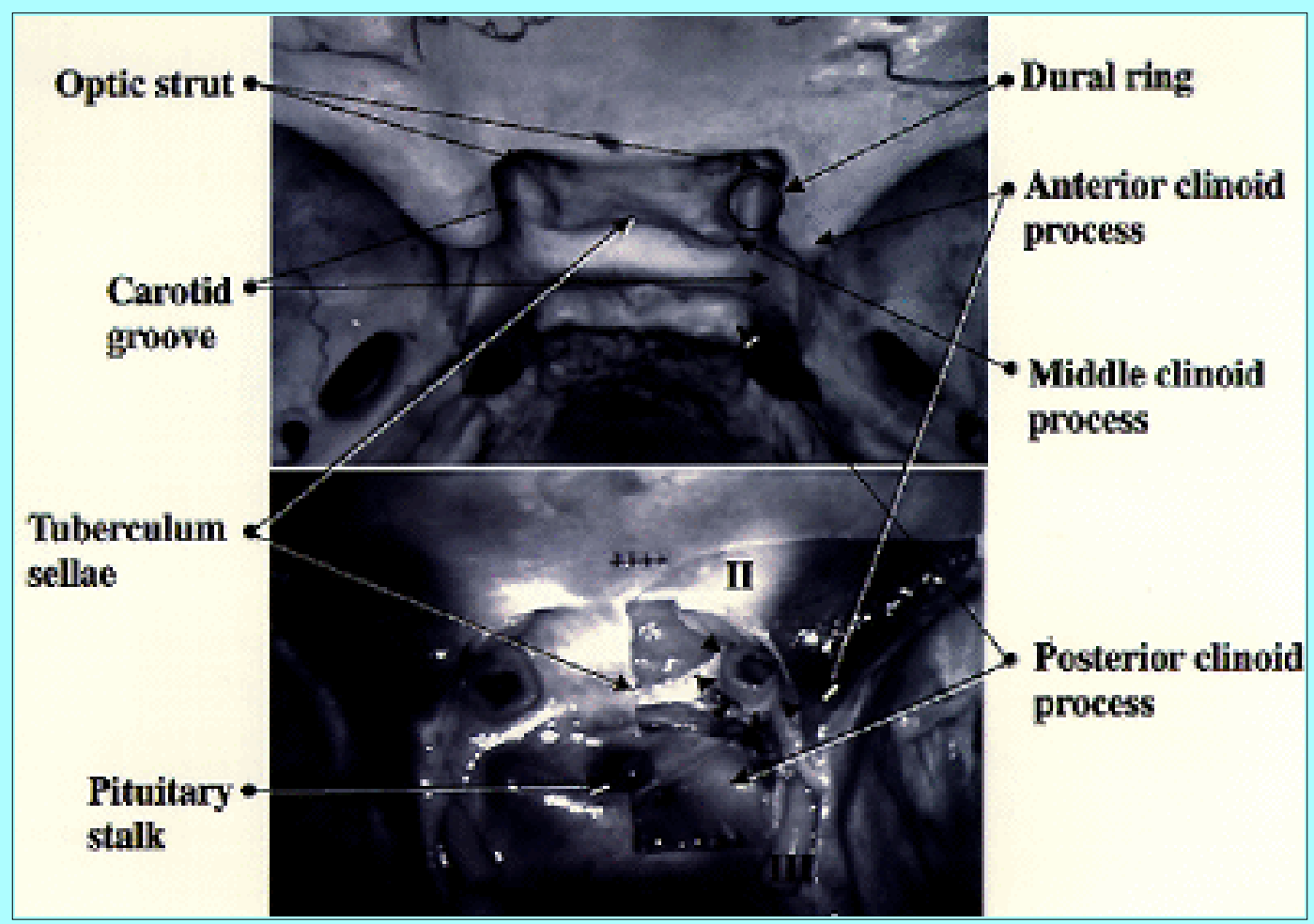

Fig. 3. Photographs presenting superior views of the juxtadural ring area in cadaver specimens, showing the relationship of bone and dural structures. Part of the dura mater around the dural ring has been removed. The dural ring (arrowheads) continues to the diaphragma sellae posteromedially and to the dura mater covering the tuberculum sellae or middle clinoid process anteromedially. II = second cranial nerve; III = third cranial nerve.

The plane of the dural ring inclines in the posteromedial direction. Medial inclination was measured on radiographic studies at 14 to 31 š (mean 21.8š) in the AP view in nine specimens (Figs. 1 and 2 upper). Posterior inclination was measured at 5 to 43š (mean 20.3š) in the lateral projection in nine specimens (Figs. 1 and 2 lower).

In the lateral projection of the radiographic studies, the medial edge of the dural ring was situated at -1.2 to $2.2 \mathrm{~mm}$ (mean $0.4 \mathrm{~mm}$ ) above the tuberculum sellae in nine specimens, corresponding mostly to the level of the tuberculum sellae. The dural ring's lateral edge was located at 0 to $2.7 \mathrm{~mm}$ (mean $1.4 \mathrm{~mm}$ ) below the superior border of the anterior clinoid process in seven specimens (Figs. 1 and 2 lower, and 4 left). 


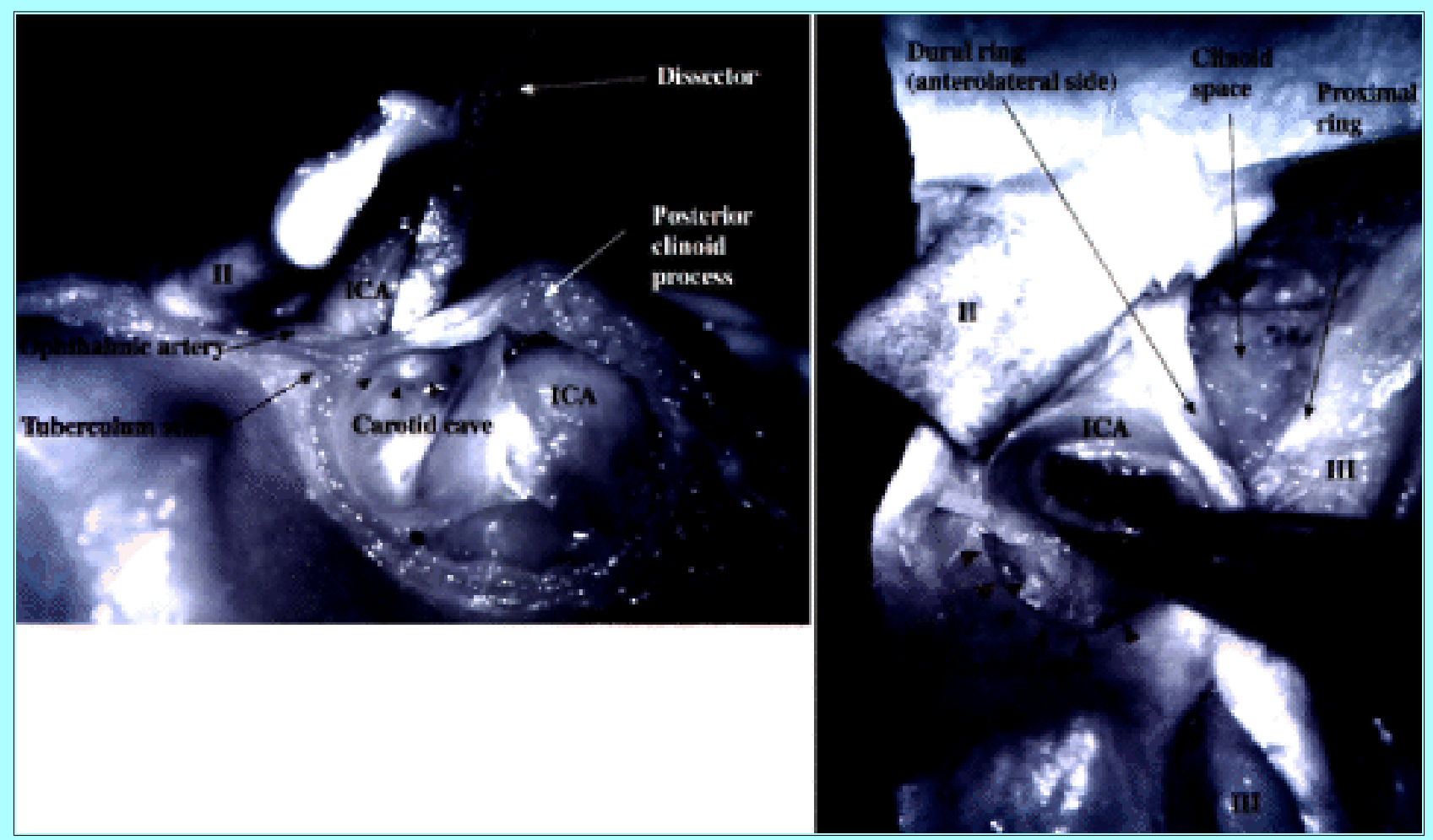

Fig. 4. Photographs obtained while dissecting cadaver specimens. Left: Medial view of the right juxtadural ring area. The tip of the silver dissector is inside the carotid cave. Right: Superior view of the right juxtadural ring area. The anterior clinoid process has been removed. Arrowheads indicate the carotid cave, which is located between 5 and 9 o'clock. II $=$ second cranial nerve; III = third cranial nerve.

\section{Carotid Cave}

The carotid cave did not exist at the dural ring in two of the 20 sides of the cadaver specimens (Table 1). The carotid caves were located at the medial or posteromedial aspect of the dural ring (Fig. 4); they were measured between 5 and 12 o'clock with the mean apex at 8.8 o'clock. In the 18 sides containing the carotid cave, its depth was measured at 0.5 to $3.2 \mathrm{~mm}$ (mean $1.6 \mathrm{~mm}$ ). Concerning the contents of the cave, the subarachnoid space was found extending into the carotid cave in 13 sides, the arachnoid membrane only was present in three sides, and two caves contained the extraarachnoid space. The bottoms of all caves consisted of fragile connective tissue, which corresponded to the superior border of the venous space extending to the cavernous sinus (infraclinoid carotid groove sinus).[11] 
TABLE 1

MEASUREMENTS OF THE CAROTID CAYE IN 20 CADAYER SPEC MENS

\begin{tabular}{|c|c|c|c|c|c|c|}
\hline $\begin{array}{c}\text { Speci- } \\
\text { men No. }\end{array}$ & Side & Cave & $\begin{array}{l}\text { Loca- } \\
\text { tiont }\end{array}$ & Apex & $\begin{array}{l}\text { Depth } \\
(\mathrm{mm})\end{array}$ & Conterts \\
\hline 1 & $r t$ & yes & $7-9$ & 8 & 1.0 & subarachnoid space \\
\hline 2 & $\mathrm{rt}$ & yes & $7-11$ & 9 & 1.4 & arachnoid mem trane \\
\hline 3 & $r t$ & yes & $6-10$ & 9 & 1.5 & subarachnoid space \\
\hline 4 & $\mathrm{rt}$ & no & & & & \\
\hline 5 & It & yes & $6-11$ & 8 & 2.0 & subarachnoid space \\
\hline 6 & $\mathrm{rt}$ & yes & $6-9$ & 7 & 1.0 & subarachnoid space \\
\hline 7 & $\mathrm{rt}$ & yes & $8-10$ & 9 & 1.0 & subarachnoid space \\
\hline 8 & It & yes & $5-11$ & 8 & 1.5 & subarachnoid space \\
\hline 9 & $r t$ & yes & $8-12$ & 10 & 1.0 & arachnoid mem trane \\
\hline 10 & $\mathrm{rt}$ & yes & $7-12$ & 9 & 2.0 & subarachnoid space \\
\hline 11 & It & yes & $8-10$ & 9 & 0.5 & extraarachnoid space \\
\hline 12 & $\mathrm{rt}$ & yes & $7-10$ & 9 & 1.5 & extraarachnoid space \\
\hline 13 & It & yes & $7-11$ & 9 & 1.5 & subarachnoid space \\
\hline 14 & It & yes & $6-11$ & 9 & 2.0 & subarachnoid space \\
\hline 15 & rt & no & & & & \\
\hline 16 & It & yes & $7-10$ & 9 & 1.2 & subarachnoid space \\
\hline 17 & It & yes & $5-9$ & 8 & 2.0 & arachnoid mem trane \\
\hline 18 & It & yes & $6-12$ & 9 & 2.2 & subarachnoid space \\
\hline 19 & $\mathrm{rt}$ & yes & $6-11$ & 10 & 3.2 & subarachnoid space \\
\hline 20 & It & yes & $6-12$ & 10 & 2.0 & subarachnoid space \\
\hline & & 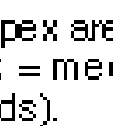 & & & & $\begin{array}{l}\text { s follows: } 12 \text { o'clock } \\
\text { ock = lateral (see ma }\end{array}$ \\
\hline
\end{tabular}

\section{DISCUSSION}

\section{General Anatomy}

The ICA enters the intradural space through the dura mater, forming the carotid siphon. It was called the $\mathrm{C}_{3}$ segment by Fischer[6] and the clinoid or paraclinoidal segment by various other authors.[2,5,9] We call the penetrating area of the ICA, which consists of complicated anatomical structures, the juxtadural ring area.[11] Before entering intradural space, the ICA passes through thin membrane, which is considered to be essentially the periosteum of the anterior clinoid process; Dolenc[4] called the penetration site the proximal ring. It was called the caroticooculomotor membrane by Inoue, et al.[9] The proximal ring forms the superior border of the cavernous sinus. We emphasize that the proximal ring is apparent only in the lateral side of the ICA. Passing through the proximal ring, the ICA penetrates the true dura (dura propria). This was termed the fibrous ring by Perneczky, et al.,[14] and Dolenc[4] called it the distal or dural ring. We call it the dural ring, because the ring consists of the true dura and it is the strict border between the extra- and intradural space.[11] The segment of the ICA between the two rings is defined as the clinoid or infraclinoid segment.[4,9,11]

Removal of the anterior clinoid process provides a clear exposure of the two rings and the clinoid segment of the ICA, and the space made by removal of the process between the two rings corresponds to the clinoid or infraclinoid space.[4,9,11] The carotid cave is situated at the medial aspect of the dural ring and contains the subdural space. An aneurysm arising from it is known as a carotid cave aneurysm of the ICA;[10] however, this concept is often misunderstood.[3,17] The clinoid space is distinct from the carotid cave because the former is situated in the lateral aspect of the ICA and corresponds to extracavernous and extradural space. 


\section{Location of the Intradural ICA}

One of the most interesting and important problems in clinical neurosurgery is the question of where the intradural portion of the ICA starts. Punt[15] proposed that the origin of the ophthalmic artery (OA) becomes the marker pointing to the dural ring. The anterior clinoid process was proposed by Taptas[18] as a better marker to identify the intradural space along the ICA. Our study confirms that the dural ring inclines toward the posteromedial direction, a finding that was first described by Nutik.[12] Therefore, the most distal (superior) point of the dural ring corresponds to its anterolateral side and its marker is considered to be the superior border of the anterior clinoid process. We agree with Taptas on this point. On the other hand, the most proximal (inferior) point of the dural ring is its posteromedial edge extending to the diaphragma sellae, which is attached to the tuberculum sellae anteriorly. Therefore, as our study shows, the proximal marker of the dural ring is considered to be the tuberculum sellae. The OA originates from the anterior or anteromedial wall of the ICA,[16] which may be more distal than the posteromedial edge of the dural ring because of its inclination; therefore, the intradural space starts more proximally than the origin of the OA. Moreover, the carotid cave is located at the medial or posteromedial side of the dural ring, which mainly contains the subarachnoid space. As a result the subarachnoid space can extend under the level of the tuberculum sellae in the medial aspect, which means that an aneurysm located at the medial aspect of the juxtadural ring area may cause a subarachnoid hemorrhage.

\section{CONCLUSIONS}

We propose that the marker of the medial side of the dural ring, which is more proximal than the lateral, is the tuberculum sellae in the lateral view on radiographic studies. When the carotid cave exists, the border between the intra- and extradural spaces in the medial aspect of the dural ring shifts to a more proximal location. We conclude that an aneurysm originating even below the level of the tuberculum sellae in the juxtadural ring area can cause subarachnoid hemorrhage.

\section{Acknowledgments}

We thank Professor Tetsuji Moriizumi of the Department of Anatomy at the Shinshu University School of Medicine for providing us with cadaver specimens, and Dr. Toshihide Toriyama for helpful suggestions.

\section{References}

1. Al-Rodhan NRF, Piepgras DG, Sundt TM Jr: Transitional cavernous aneurysms of the internal carotid artery. Neurosurgery 33:993-998, 1993

2. Bouthillier A, van Loveren HR, Keller JT: Segments of the internal carotid artery: a new classification. Neurosurgery 38:425-433, 1996

3. Day AL: Aneurysms of the ophthalmic segment. A clinical and anatomical analysis. J Neurosurg 72:677-691, 1990

4. Dolenc VV: Anatomy and Surgery of the Cavernous Sinus. Vienna: Springer-VerIag, 1989

5. Dolenc VV: A combined epi- and subdural direct approach to carotid-ophthalmic artery aneurysms. J Neurosurg 62:667-672, 1985 
6. Fischer E: Die Lageabweichungen der vorderen Hirnarterie im Gefässbild. Zentralbl Neurochir 3:300-313, 1938

7. Gibo H, Lenkey C, Rhoton AL Jr: Microsurgical anatomy of the supraclinoid portion of the internal carotid artery. J Neurosurg 55:560-574, 1981

8. Guidetti B, La Torre E: Management of carotid-ophthalmic aneurysms. J Neurosurg 42:438-442, 1975

9. Inoue T, Rhoton AL Jr, Theele D, et al: Surgical approaches to the cavernous sinus: a microsurgical study. Neurosurgery 26:903-932, 1990

10. Kobayashi S, Kyoshima K, Gibo H, et aI: Carotid cave aneurysms of the internal carotid artery. J Neurosurg 70:216-221, 1989

11. Kyoshima K, Koike G, Hokama M, et al: A classification of juxta-dural ring aneurysms with reference to surgical anatomy. J Clin Neurosci 3:61-64, 1996

12. Nutik SL: Removal of the anterior clinoid process for exposure of the proximal intracranial carotid artery. J Neurosurg 69:529-534, 1988

13. Nutik SL: Ventral paraclinoid carotid aneurysms. J Neurosurg 69:340-344, 1988

14. Perneczky A, Knosp E, Vorkapic P, et al: Direct surgical approach to infraclinoidal aneurysms. Acta Neurochir 76:36-44, 1985

15. Punt J: Some observations on aneurysms of the proximal internal carotid artery. J Neurosurg 51:151-154, 1979

16. Renn WH, Rhoton AL Jr: Microsurgical anatomy of the sellar region. J Neurosurg 43:288-298, 1975

17. Sadasivan B, Ma SH, Dujovny M, el al: The anterior cavernous sinus space. Acta Neurochir 108:154-158, 1991

18. Taptas JN: Intradural and extradural ICA. J Neurosurg 51:877-878, 1979 (Letter)

19. Umansky F, Valarezo A, Elidan J: The superior wall of the cavernous sinus: a microanatomical study. J Neurosurg 81:914-920, 1994

20. Yas[cedilla under "s" in "Yasargil"]argil MG: Microneurosurgery. Stuttgart: Thieme, 1984, Vol 2, pp 60-70

Manuscript received September 24, 1997.

Accepted in final form March 2, 1998.

Address reprint requests to: Susumu Oikawa, M.D., Department of Neurosurgery, Shinshu University School of Medicine, Asahi 3-1-1, Matsumoto 390, Japan. 